\title{
Validation of the anti-bacteremic efficacy of an essential oil rinse in a Brazilian population: a cross-over study
}

\section{José Roberto Cortelli(a) \\ Karina Cogo(a) \\ Davi Romeiro Aquino(a) \\ Sheila Cavalca Cortelli(a) \\ Danette Ricci-Nittel(b) \\ Paul Zhang(b) \\ Marcelo Werneck Barata de \\ Araujo(b)}

(a) Nucleus of Periodontal Research - NUPER, Department of Periodontology, Dentistry School, Univ of Taubate, Taubate, SP, Brazil.

(b) Johnson \& Johnson Consumer \& Personal Products Worldwide, Division of Johnson \& Johnson Consumer Companies Inc., Morris Plains, NJ, USA.

Declaration of Interests: The study was funded by a grant from the Johnson and Johnson Consumer Companies Inc.

\section{Corresponding Author:}

Marcelo Werneck Barata de Araujo

Email:mwbaravjo@yahoo.com

Submitted: Feb 01, 2012

Accepted for publication: May 02, 2012

Last revision: Jun 12, 2012

\begin{abstract}
This cross-over study was conducted to assess the germ-killing efficacy of an essential oil mouthrinse (EOM) by determining the blood levels of microorganisms associated with induced bacteremia and investigating the prevalence of this event in Brazilians with mild-to-moderate gingivitis. Thirty four (31.19\%) subjects positive for bacteremia induced by chewing a ration of apple were enrolled out of 109 screened subjects (50 males and 59 females). A difference of at least 10 colony forming units between the pre- and post-insult blood samples was defined as a positive result. For the following two weeks patients underwent a toothbrush plus fluoride dentifrice normalization period, and were then scheduled for the Phase I protocol as follows. At baseline I, subjects were instructed to chew a new apple ration, had new blood samples taken before and after this oral stimulus, and were randomly assigned to an experimental essential oil $(n=17)$ or placebo $(P)$ mouthrinse $(n=17)$ treatment for 2 weeks. These procedures were repeated at the end of Phase I and then followed by a two-week wash-out period (tooth brushing with fluoride dentifrice). Bacteremia was again induced at baseline and at the end of Phase II, when subjects were crossed-over to the other EOM or placebo groups. Bacterial count differences between baseline and 2-week post-treatment (EOM versus $\mathrm{P}$ ) in the blood samples collected were assessed by analysis of covariance. Mean aerobic counts decreased by $45.8 \%$, whereas mean anaerobic counts decreased by $63.3 \%$ after EOM treatment. After the P treatment, aerobic bacteria increased by $28.4 \%$ and anaerobic bacteria decreased by $18.5 \%$. This study validated this novel methodology and showed that the germ-killing action of EOM significantly reduced bacteremia.
\end{abstract}

Descriptors: Bacteremia; Gingivitis; Efficacy; Bacteria.

\section{Introduction}

The term bacteremia was coined in the $19^{\text {th }}$ century when bacteria and fungi were placed within the same taxonomic group. ${ }^{1}$ Cell culture techniques are frequently used to determine the prevalence of bacteria in the blood, associated with different infections. ${ }^{2}$

Currently, researchers recognize that the oral cavity is intensely colonized by bacteria. Paster et al. ${ }^{3}$ stated that dental biofilm contains over 700 species of aerobic and anaerobic bacteria. Parahitiyawa et al. ${ }^{4} \mathrm{dem}-$ onstrated that bacteria gain entry into the bloodstream from oral nich- 
es through a number of mechanisms and a variety of portals. Bacteria first have access to the bloodstream through tissue trauma, such as tooth brushing, chewing food, tooth extractions, and periodontal procedures like scaling and root planing or probing. ${ }^{5}$ When tissue trauma occurs, breakage of the capillaries and smaller blood vessels neighboring plaque biofilms may lead to bacteria spilling into the systemic circulation. Innate microbial factors, such as virulence attributes, may influence this process, since only a few species are detected in experimental bacteremia despite the multitude of diverse bacteria residing within the periodontal biofilm. ${ }^{4}$

The link between dental procedures and resultant bacteremia has been under scrutiny for more than half a century. In 1954, Cobe, evaluating a large number of subjects, found that the highest incidence of bacteremia was related to periodontal cleaning $(40 \%)$, followed by exodontia $(35 \%)$, brushing (24\%), and hard mastication $(17 \%) .{ }^{6}$ In addition, Forner et al. indicated that higher microbial loads would facilitate such disseminations; ${ }^{2}$ it is well known that individuals with poor oral hygiene are at a higher risk of developing bacteremia during oral manipulative procedures.

Antiseptic mouthrinses are effective and widely used agents to maintain whole-mouth cleanliness and to control gingivitis. Essential-oil-containing mouthrinses (EOM) have shown anti-plaque and anti-gingivitis properties in short ${ }^{7-9}$ and long-term clinical studies ${ }^{10-12}$ designed according to the guidelines of the American Dental Association Council on Scientific Affairs. ${ }^{13}$

Recently, Fine et al. $^{14}$ assessed the effect of an EOM in reducing bacteria in the mouth of mild gingivitis patients, and in subsequently decreasing the levels of bacteria in the bloodstream, after chewing an apple. The authors reported that rinsing with EOM twice a day for 30 seconds led to an almost $70 \%$ reduction in bacteremia levels after 2 weeks of use. A similar study was conducted in Brazil, aiming at supporting this new methodology and extending its applicability to other populations. Thus, this randomized, single-centered, double-blind, controlled, two-week, cross-over clinical trial, aimed at

- (1) assessing the germ-killing efficacy of rinsing twice daily with an EOM by determining the levels of oral bacteria in the bloodstream resulting from an induced bacteremia event, and

- (2) investigating the prevalence of bacteremia in a Brazilian population with mild-to-moderate gingivitis.

\section{Methodology}

Medical and dental histories of the subjects were obtained through a questionnaire. An informed consent form, previously approved by the Institutional Committee on Research Involving Human Subjects of the University of Taubate - UNITAU (protocol 527/09), was signed by all subjects. The present study design was similar to that used by Fine et al. ${ }^{14}$

\section{Subjects}

An eligible sample population was screened from a total of 400 subjects drawn from a database kept by the Nucleus of Periodontal Research (NUPER/ UNITAU), Paraíba Valley region, São Paulo, Brazil, from August 2009 to December 2010. After screening for inclusion/exclusion criteria, 109 Brazilian multiethnic subjects were recruited for the study.

\section{Inclusion criteria}

Male or female patients, 18 years of age or older, in good general and dental health, with a minimum of 20 natural teeth with scorable facial and lingual surfaces, showing mild-to-moderate gingivitis were included. Subjects being treated for chronic conditions were included if their conditions were under control and stable for at least three months prior to their participation in the study. Participants were required to have a modified gingival index $(\mathrm{MGI})^{15}$ score $\geq 1.50$ and a plaque index (PI) score $\geq 1.50$ using the Turesky modification of the Quigley Hein Index. ${ }^{16}$

\section{Exclusion criteria}

Subjects presenting any of the following conditions were excluded from the study:

- (1) history of adverse effects following use of toothpastes and mouthrinses;

- (2) history of rheumatic fever, heart murmur or 
defect, orthopedic implants, or any other condition requiring prophylactic antibiotic therapy;

- (3) history of an adverse event following venipuncture;

- (4) history of diabetes or hepatic or renal disease;

- (5) antibiotic therapy during the month preceding the baseline exam;

- (6) self-reported pregnancy or lactation;

- (7) significant oral soft tissue pathology, excluding gingivitis, based on a visual examination;

- (8) fixed or removable orthodontic appliance or removable partial dentures;

- (9) teeth with gross dental caries, large fractured or temporary restorations or severe generalized cervical abrasion and/or enamel abrasion;

- (10) regular use of chemotherapeutic antiplaque/ antigingivitis products within 2 weeks prior to the screening;

- (11) participation in a dental plaque study within the last 30 days.

\section{Initial screening}

One hundred and nine subjects who met these initial entry criteria were screened for possible entry into the study, with a projection that at least 30 subjects would complete the study sample.

\section{Overall study design and plan}

Subjects received an oral explanation about the research protocol, followed by a demonstration of bacteremia procedures. At the first visit, subjects presented for oral examinations, having refrained from oral hygiene, eating, drinking (except for water) and smoking for at least 12 hours, but no more than 24 hours, prior to screening. These requirements were adopted for all subsequent visits. In a second visit, subjects were tested for the bacteremia event. A pre-insult blood sample $(2 \mathrm{ml})$ was collected to establish any detectable level of bacteria in all the blood. The subjects were then asked to chew and swallow three pieces of an apple uninterruptedly. Immediately after a volunteer had taken the first bite, a trained researcher recorded the time on a digital chronometer. A second, post-insult blood sample $(2 \mathrm{ml})$ was collected within 2 minutes \pm 30 seconds, based on when the masticatory cycle for the first piece of the apple was initiated. Blood samples were used to determine whether or not subjects had bacteremia, defined as a difference (post-insult minus pre-insult) of at least 10 colony forming units $(\mathrm{CFU} / \mathrm{ml})$. Those subjects who met the general inclusion/exclusion criteria and who also were positive for bacteremia were randomly assigned to one of the two treatment sequences (Phase I and II). The treatments consisted of an EOM (Listerine Antiseptic, Johnson \& Johnson Inc., Morris Plains, USA) and a placebo rinse $(\mathrm{P})$. A computer generated random $\mathrm{EOM} /$ placebo sequence was provided by the sponsor of the study, and the volunteer allocation process was based on sealed opaque envelopes. To ensure study blindness, the bottles of the mouthrinses were overwrapped with new labels, numbered with the randomization code and containing the rinsing directions, but no other identifying information. The placebo was packaged identically to the EOM products. Besides dispenser personnel, other researchers that had any contact with participants were blinded to treatment assignment for the duration of the study and completion of the statistical analysis.

A total of ten blood samples were collected per volunteer, five pre- and five post-insult:

- screening,

- baseline Phase I,

- final Phase I,

- baseline phase II and

- final Phase II.

\section{Normalization of the sample}

During a two-week normalization period, subjects received instructions to use a fluoride dentifrice and soft-bristled toothbrush twice a day in their usual manner. They were also instructed not to use any other oral hygiene product other than the one supplied for the duration of the study.

\section{Phase I}

After normalization of the sample, pre-screened subjects positive for bacteremia returned to Phase I baseline examinations. Pre- and post-insult blood draws were performed at baseline and at the end of Phase I, as described for the previous apple mastication insult. Subjects were provided with their as- 
signed mouthrinse (EOM [ $=17]$ or $\mathrm{P}[\mathrm{n}=17])$, a toothbrush and fluoride toothpaste. At the end of the visit, subjects brushed their teeth in their usual manner and then performed the first supervised rinse $(20 \mathrm{ml}$ of EOM or $\mathrm{P}$ for 30 seconds). They were then instructed to repeat this process twice a day (morning and night) for an additional period of two weeks. The use of the product was supervised during the week and unsupervised during weekends, when subjects recorded the time of rinsing on a diary card. After 14 days of rinsing, that is, on day 15, subjects were submitted to the apple chewing insult again, preceded and followed by blood draws.

\section{Wash-out period}

There was a two-week wash-out period before Phase II, when subjects only performed mechanical plaque control (brushing with fluoride dentifrice).

\section{Phase II}

After the wash-out period, subjects from Phase I were crossed-over to the other treatment group ( $\mathrm{P}$ $[\mathrm{n}=17]$ or EOM [ $\mathrm{n}=17])$ as determined by a computer, and then the baseline blood examinations, the treatment regimen and the final blood examinations were repeated as described for Phase I.

\section{Microbiological assessment}

Blood samples $(2 \mathrm{ml})$ were collected into a citrated Vacutainer ${ }^{\circledR}$ tube. One milliliter was pipetted from the tube and poured into a second tube containing $1 \mathrm{ml}$ of a $1 \%$ sterile solution of sodium polyanethol sulfonate (Sigma Chemical Co., St. Louis, USA) to deactivate complement proteins. After collection, blood samples were immediately spread out onto agar plates, in duplicate. Tryptic Soy Agar (TSA), incubated for 2 days at $35^{\circ} \mathrm{C}$, was used to determine total aerobic counts, while Schaedler Blood Agar (SBA), incubated for 5-7 days at $35^{\circ} \mathrm{C}$, was used to determine total anaerobic counts. Bacterial colonies were counted by an automated colony counting system. For additional microbiological details, please see Fine et al. ${ }^{14}$

\section{Statistical analysis}

\section{Sample size determination}

Based on a previous study by Fine et al. ${ }^{14}$ it was estimated that 24 subjects were needed to complete both Phase I and Phase II treatments. This sample size provided a power of at least $90 \%$ to detect a $20 \mathrm{CFU} / \mathrm{ml}$ treatment difference between EOM and placebo. The study was based on a two-sided test $(\mathrm{p}<0.05)$. Considering a possible attrition rate, a total of 34 subjects were randomized into the study.

\section{Efficacy evaluations}

Induced bacteria level was defined as the postinsult bacteria level minus the pre-insult bacteria level. Descriptive statistics and graphics were used to summarize the induced bacteria level of total bacteria in the counts $(\mathrm{CFUs} / \mathrm{ml})$, by treatment group. The reduction in the induced bacteria level of total bacteria counts from baseline to day 15 in each treatment phase was analyzed using an analysis of covariance (ANCOVA). The model included treatment sequence, phase, and treatment as variables (factors). The total of blood-borne bacteria at baseline of each phase was used as a covariate and the subject within the treatment sequence was considered as a random effect.

\section{Results}

Of the 109 subjects (mean age $29.88 \pm 10.14$ ) 50 males (mean age $32.88 \pm 10.81$ ) and 59 females (mean age $27.55 \pm 9.01)-34(31.19 \%)$ tested positive for bacteremia, and 75 (68.80\%) were negative. All positive subjects were successfully allocated to the treatments. There was no drop-out during the study. The demographic characteristics of the bacteremia-positive subjects are shown in Table 1 .

The levels of induced total aerobic and anaerobic bacteria in the blood, calculated as the difference between post-insult $\mathrm{CFU} / \mathrm{ml}$ counts and pre-insult counts, at baseline and at day 15 , are shown in Tables 2 and 3, respectively.

\section{Discussion}

The present study investigated the prevalence of bacteremia in a Brazilian population with gingivitis and assessed the germ-killing efficacy of an EOM by 
Table 1 - Demographic characteristics of 34 bacteremiapositive subjects.

\begin{tabular}{|c|c|c|c|}
\hline & $\begin{array}{c}\text { Placebo (Phase I) } \\
\text { Essential oils (Phase II) } \\
n=17\end{array}$ & $\begin{array}{c}\text { Essential oils (Phase I } \\
\text { Placebo (Phase II) } \\
n=17\end{array}$ & Total $=34$ \\
\hline Age & $30.18 \pm 10.09$ & $31.53 \pm 11.55$ & $30.85 \pm 10.70$ \\
\hline \multicolumn{4}{|c|}{ Gender } \\
\hline Male & $11(64.7 \%)$ & 7 (41.2\%) & 18 (52.9\%) \\
\hline Female & $6(35.3 \%)$ & 10 (58.8\%) & $16(47.1 \%)$ \\
\hline \multicolumn{4}{|c|}{ Race } \\
\hline White & 14 (82.4\%) & 15 (88.2\%) & 29 (85.3\%) \\
\hline Black & $1 \quad(5.9 \%)$ & - & $1 \quad(2.9 \%)$ \\
\hline Others & 2 (1 1.8\%) & $2(11.8 \%)$ & $4(11.8 \%)$ \\
\hline \multicolumn{4}{|c|}{ Tobacco use } \\
\hline No & 16 (94.1\%) & 15 (88.2\%) & 31 (91.2\%) \\
\hline Yes & $1 \quad(5.9 \%)$ & 2 (11.8\%) & 3 (8.8\%) \\
\hline
\end{tabular}

Table 2 - Induced anaerobic bacteria level (CFU/ml) in both the EOM and the placebo groups, combining counts from Phases I and II.

\begin{tabular}{c|c|c}
\hline & Essential oils $=34$ & Placebo $=34$ \\
\hline $\begin{array}{c}\text { Induced bacteria level } \\
\text { at baseline (CFU/ml) }\end{array}$ & $107.29( \pm 110.96)$ & $112.41( \pm 104.88)$ \\
\hline $\begin{array}{c}\text { Induced bacteria level } \\
\text { at day 15 (CFU/ml) }\end{array}$ & $26.17( \pm 23.10)$ & $83.76 \quad \pm 53.36)$ \\
\hline $\begin{array}{c}\text { Change from baseline } \\
\text { induced bacteria level }\end{array}$ & $-81.12( \pm 108.48)$ & $\begin{array}{r}-28.65 \quad \pm 90.06) \\
P<0.001\end{array}$ \\
\hline $\begin{array}{c}\text { Percentage of change of } \\
\text { induced bacteria level }\end{array}$ & $-63.29 \%$ & $-18.53 \%$ \\
\hline
\end{tabular}

determining the levels of oral microorganisms in the bloodstream resulting from an induced bacteremic event.

Historically, bacteremia derived from traumatized tissues has provided a direct link between oral and systemic infections. ${ }^{4}$ Transient bacteremia, detectable by means of blood culture, may result from two actions:

- dental manipulation (studies have shown that some patients may show an increase in bacterial levels in their blood stream following an insult such as dental treatments ${ }^{2,6}$ ) and

- daily life activities, such as eating, chewing gum, tooth brushing or using toothpicks. ${ }^{2}$

Reinforcing the potential of EOMs to prevent
Table 3 - Induced aerobic bacteria level (CFU/ml) in both the EOM and placebo groups, combining counts from Phases I and II.

\begin{tabular}{c|c|c}
\hline & Essential oils $=34$ & Placebo $=34$ \\
\hline $\begin{array}{c}\text { Induced bacteria level } \\
\text { at baseline (CFU/ml) }\end{array}$ & $41.70( \pm 48.12)$ & $42.88( \pm 50.30)$ \\
\hline $\begin{array}{c}\text { Induced bacteria level } \\
\text { at day 15 (CFU/ml) }\end{array}$ & $11.35( \pm 13.11)$ & $56.41( \pm 38.72)$ \\
\hline $\begin{array}{c}\text { Change from baseline } \\
\text { induced bacteria level }\end{array}$ & $-30.35( \pm 39.06)$ & $\begin{array}{c}+13.84( \pm 28.18) \\
P<0.001\end{array}$ \\
\hline $\begin{array}{c}\text { Percentage of change of } \\
\text { induced bacteria level }\end{array}$ & $-45.82 \%$ & $+28.40 \%$ \\
\hline
\end{tabular}

bacteremia seemed quite justifiable, since they have a broad-spectrum bactericidal action and have demonstrated significant efficacy against oral pathogens, ${ }^{14}$ including species that lead to the development of plaque and gingivitis. ${ }^{17}$ In a previous study using a similar protocol, Fine et al. ${ }^{14}$ showed that the use of an EOM for two weeks resulted in a significant reduction of blood-borne bacteria in a susceptible group of subjects. The present study investigated the prevalence of bacteremia in a Brazilian population with gingivitis, and assessed the germkilling efficacy of an EOM by determining the levels of oral microorganisms in the bloodstream resulting from an induced bacteremic event.

Regarding subject susceptibility to bacteremia, it should be mentioned that approximately $31 \%$ of 
the 109 subjects in the present study were positive for induced bacteremia according to the screening criteria. The findings of the present study were similar to those of Fine et al.,${ }^{14}$ according to which approximately $30 \%$ of subjects with comparable clinical status were susceptible to bacteremia; this same group of subjects seemed to be repeatedly susceptible to bacteremic infections. This data supports the concept that daily activities render a subset of subjects vulnerable to multiple blood-borne bacteria exposures. It was expected that the prevalence results of our study would be similar to those of Fine et al. ${ }^{14}$ because we used the same study design, in which subjects were asked to refrain from oral hygiene for a $12-\mathrm{h}$ period. This procedure allowed plaque to accumulate, perhaps adding to the level of the bacterial challenge.

As stated by Cobe $^{6}$ and later confirmed by Gunderoth, ${ }^{18}$ the frequency and duration of bacteremia after dental procedures varies largely, e.g., the frequency of bacteremia caused by tooth brushing is approximately $26 \%$, with a duration of less than 15 minutes. Most dental procedures cause bacteremia within 5 minutes, but it is normally eliminated by the reticuloendothelial system and by polymorphonuclear leukocytes after 30 minutes. ${ }^{19}$ Therefore, in this study we chose to collect blood samples within 2 minutes \pm 30 seconds. Our principal finding was that the levels of total aerobic bacteria in the bloodstream decreased from $41.7 \mathrm{CFU} / \mathrm{ml}$ at baseline to 11.3 CFU/ml after 15 days $(\mathrm{p}<0.001)$ in the EOM group. The levels of total anaerobic bacteria decreased from 107.2 CFU/ml at baseline to $26.1 \mathrm{CFU} /$ $\mathrm{ml}$ after 15 days $(\mathrm{p}<0.001)$. The magnitude of the anti-anaerobic bacteremia effect found in our study was compatible with that observed by Fine et al. ${ }^{14}$ In their study, the EOM caused a reduction of $70.2 \%$, whereas, in ours, a reduction of $63.29 \%$ was ob-

\section{References}

1. Bulloch W. The History of Bacteriology. New York: Dover Publication, Inc.; 1979.

2. Forner L, Larsen T, Kilian M, Holmstrup P. Incidence of bacteremia after chewing, tooth brushing and scaling in in- served. Although the EOM produced an aerobic level reduction in both studies, the percentages differed numerically. Fine et al. ${ }^{14}$ reported a reduction of $67.3 \%$ whereas we observed a reduction of $45.82 \%$. Therefore, the EOM demonstrated a moderate-tohigh overall effect against induced bacteremia in susceptible subjects. Bacteremia levels in the control group (placebo) were relatively unchanged. This data confirmed that rinsing regularly with an EOcontaining mouthrinse twice a day can reduce the level of blood-borne bacteria caused by a standardized challenge such as that of chewing an apple. It seems reasonable to assume that maintaining good oral hygiene practices, including tooth brushing, flossing and using an effective antimicrobial mouthrinse agent regularly, contributes to preventing periodontal disease, ${ }^{7-12}$ which, in turn, leads to a lower risk of developing bacteremia.

As stated by Schønheyder and Søgaard, ${ }^{20}$ holding knowledge of the occurrence and outcome of bacteremia is important to establish its burden of illness and to guide appropriate allocation of limited healthcare and research resources. Population-based studies are optimal to describe the epidemiology of bacteremia because a well defined catchment area allows determining incidence rates and identifying risk factors.

\section{Conclusions}

This randomized, 2-week, cross-over study suggests that bacteria enter the circulation through the gingival pocket epithelial barrier at the site of trauma, which may be caused by a daily activity. Additionally, It showed that the germ-killing action of an EOM significantly reduced bacteremia in susceptible subjects, and that the prevalence of bacteremia in an allocated Brazilian population with mild-tomoderate gingivitis was approximately $31 \%$.

dividuals with periodontal inflammation. J Clin Periodontol. 2006 Jun;33(6):401-7.

3. Paster BJ, Olsen I, Aas JA, Dewhirst FE. The breadth of bacterial diversity in the human periodontal pocket and other oral sites. Periodontol 2000. 2006 Oct;42(1):80-7. 
4. Parahitiyawa NB, Jin LJ, Leung WK, Yam WC, Samaranayake LP. Microbiology of odontogenic bacteremia: beyond endocarditis. Clin Microbiol Rev. 2009 Jan;22(1):46-64.

5. Kinane DF, Riggio MP, Walker KF, MacKenzie D, Shearer B. Bacteraemia following periodontal procedures. J Clin Periodontol. 2005 Jul;32(7):708-13.

6. Cobe HM. Transitory bacteremia. Oral Surg Oral Med Oral Pathol. 1954 Jun;7(6):609-15.

7. Mankodi SM, Ross NM, Mostler K. Clinical efficacy of Listerine in inhibiting and reducing plaque and experimental gingivitis. J Clin Periodontol. 1987 May;14(5):285-8.

8. Ross NM, Mankodi SM, Mostler KL, Charles CH, Bartels LL. Effect of rinsing time on antiplaque-antigingivitis efficacy of Listerine. J Clin Periodontol. 1993 Apr;20(4):279-81.

9. Amini P, Araujo MW, Wu MM, Charles CA, Sharma NC. Comparative antiplaque and gingivitis efficacy of three antiseptic mouthrinses: a two week randomized clinical trial. Braz Oral Res. 2009 Jul-Sep;23(3):319-25.

10. Sharma N, Charles CH, Lynch MC, Qaqish J, McGuire JA, Galustians JG et al. Adjunctive benefit of an essential oil containing mouthrinse in reducing plaque and gingivitis in patients who brush and floss regularly: a six-month study. J Am Dent Assoc. 2004;135(4):496-504.

11. Charles CH, Mostler KM, Bartels LL, Mankodi SM. Comparative antiplaque and antigingivitis effectiveness of a chlorhexidine and an essential oil mouthrinse: 6-month clinical trial. J Clin Periodontol. 2004 Oct;31(10):878-84.

12. Overholser CD, Meiller TF, DePaola LG, Minah GE, Niehaus C. Comparative effects of 2 chemotherapeutic mouthrinses on the development of supragingival dental plaque and gingivitis. J Clin Periodontol. 1990 Sep;17(8):575-9.

13. American Dental Association Council on Scientific Affairs. Acceptance Program Guidelines: chemotherapeutic products for control of gingivitis. Chicago: American Dental Association; 1997.

14. Fine DH, Furgang D, McKiernan M, Tereski-Bischio D, RicciNittel D, Zhang P, et al. An investigation of the effect of an essential oil mouthrinse on induced bacteraemia: a pilot study. J Clin Periodontol. 2010 Sep;37(9):840-7.

15. Lobene RR, Weatherford T, Ross NM, Lamm RA, Menaker L. A modified gingival index for use in clinical trials. Clin Prev Dent. 1986 Jan-Feb;8(1): 3-6.

16. Turesky S, Gilmore ND, Glickman I. Reduced plaque formation by the chloromethyl analogue of vitamin C. J Periodontol. 1970 Jan;41(1):41-3.

17. Pan PC, Harper DS, Ricci-Nittel D, Lux R, Shi W. In vitro evidence for efficacy of antimicrobial mouthrinses. J Dent. 2010 Jun;38 Suppl 1:S16-20.

18. Gunderoth WG. How important are dental procedures as a cause of infective endocarditis? Am J Cardiol. 1984 Oct;54(7):797-801.

19. Olsen I. Update on bacteraemia related to dental procedures. Transfus Apher Sci. 2008 Oct; 39(2):173-8.

20. Schønheyder HC, Søgaard M. Existing data sources for clinical epidemiology: the North Denmark bacteremia research database. Clin Epidemiol. 2010 Aug;9(2):171-8. 